\title{
Prevalence of Celiac Disease in Idiopathic Short Stature Children Presenting in OPD of Children Hospital, Faisalabad
}

\author{
Jaweria Masood, Hooria Rehman, Zahid Mahmood Anjum, Irum Iqbal, Sadia Zafar, Hina Ayesha
}

\begin{abstract}
Objective: To determine the prevalence of celiac disease in short statured children. Study Design: Cross Sectional Study. Settings: OPD of Children Hospital, Faisalabad Pakistan. Duration: Six months from March 10, 2016 to August 9, 2016. Methodology: A total of 300 children with 174 female, 126 males were studied, who came in OPD in Children Hospital Faisalabad for the evaluation of their short stature, excluding familial short stature and other causes of short stature (endocrinal, renal \& other chronic illnesses). IgA, TTG \& IgG antibodies were evaluated. These antibodies were measured by ELISA method and patients whose TTG antibodies were 10 times greater than normal were spared form duodenal biopsy, however patients having antibodies less than 10 times but greater than normal or having equivocal results were under gone for intestinal biopsy for confirmation of celiac disease. Results: We detected out of 300 patients 88 patients were having TTG titer $>10 \%$ of the normal value. 29 patients were having increase titer but less than 10 time of the normal value and 7 patients were found to have equivocal results. So, 36 patients were sent for biopsy out of them 32 were found positive for celiac disease. Hence, we detected $40 \%(n=120)$ children were having celiac disease. All 78 females, 42 males having celiac disease were at 2SD except 4 patients who were at 3SD. Conclusion: We conclude that prevalence of celiac disease is high in patients with idiopathic short stature and it is important to investigate all children with ISS for celiac disease by measuring TTG antibodies.
\end{abstract}

Keywords: Celiac disease, Short stature, Anti tissue transglutaminase antibodies (TTG Ab).

Corresponding Author Submitted for Publication: 23-09-2019 Accepted for Publication: 04-11-2019

DR. JAWERIA MASOOD, Senior Registrar of Pediatric Medicine, Children Hospital, Faisalabad-Pakistan.

Contact / Email: +92 332-6881436, jaweriamasood6@gmail.com

Citation: Masood J, Rehman H, Anjum ZM, Iqbal I, Zafar S, Ayesha H. Prevalence of Celiac Disease in Idiopathic Short Stature Children Presenting in OPD of Children Hospital, Faisalabad. APMC 2020;14(1):9-12.

\section{INTRODUCTION}

Celiac disease is a gluten sensitive enteropathy and genetically determined disease. ${ }^{1}$ Celiac disease may be found in up to $12 \%$ of Pakistanis presenting with nutritional anemia. ${ }^{2}$ It is an immune reaction due to eating gluten, a protein found in wheat, barley and rye. It has wide spectrum of gastrointestinal and extra gastrointestinal manifestation. Gastrointestinal manifestations are diarrhea, large bulky stool, vomiting, bloating, abdominal pain, distension and sometimes constipation. ${ }^{3}$

Extra gastrointestinal or non-classical presentation of celiac disease has become a common challenge for pediatricians, because patients present with atypical symptoms, which includes short stature, iron deficiency anemia, rickets, liver disease, reproductive disorders and thyroid disorder. ${ }^{4}$ Among these atypical symptom's short stature and iron deficiency anemia are commonest symptoms, which a pediatrician encounter. So, a clinician should keep high suspicion of celiac disease in short stature children when all other causes have been excluded.

Although the true pathogenesis of celiac disease associated short stature is still unclear i.e.: patient is short statured although he or she is not having complaint of malabsorptive stools. Perhaps there is involvement of insulin like growth factor and ghrelin (satiety stimulating hormone) that might be secreted enteroendocrine cells. ${ }^{3,5}$

Most of these patients have no identifiable medical abnormality and so are labelled as idiopathic short stature now the celiac disease is becoming a more common cause of short stature in otherwise healthy children than growth hormone deficiency. The detection rate of celiac disease is increasing worldwide and there has been a substantial change in mode of presentation of patients with celiac disease over recent years. 6,7 Globally, prevalence of celiac disease in short stature was 2 to $8 \%{ }^{8}$ Similarly, in Iran a study was carried out that reported that despite the presence of clinical signs of celiac disease during childhood in more than $1 / 3$ of patient disease remained undiagnosed, the late diagnosis may lead to short stature. ${ }^{9}$ Another study was carried out in Iran that concluded that prevalence of celiac disease was high in patients with idiopathic short stature ${ }^{10}$ and It was important to test all children with idiopathic short stature for celiac disease as timely diagnosis and treatment can enhance growth velocity.

Diagnosis of celiac disease is based on combination of symptoms, antibody titer and duodenal histology. ${ }^{11}$ The initial approach in suspected patient is anti TTG antibodies in addition to total serum IgA level followed by intestinal biopsy. ${ }^{12}$

Considering the high prevalence of celiac disease among idiopathic short stature, we planned a study in Children Hospital, Faisalabad in which we evaluated all those children for celiac disease who presented in OPD with idiopathic short stature.

Purpose of the present study was to evaluate and enhance its (celiac disease) high prevalence among short stature.

\section{METHODOLOGY}

Study Design: Cross Sectional Study.

Settings: OPD in Children Hospital Faisalabad-Pakistan.

Duration: Six months from March 2016 to August 2016.

Sample Size: 300 children. 
Inclusion Criteria: Children with age 2 to 15 years who presented in OPD with only complaint of short stature (height less than second percentile adjusted for age and sex).

Exclusion Criteria: Age less than one year. Children with chronic infections and chronic systemic diseases. Children with any physical stigmata of disease.

Methods: After taking approval from hospital ethical review committee, children fulfilling inclusion criteria were enrolled. All patients were interrogated for specific symptoms of celiac disease, malabsorptive syndromes and other chronic illnesses that can cause growth retardation. After that detailed physical examination was carried out.

The height, weight and weight for age \& height were recorded at presentation. Parental height was also taken to calculate mid parental height to exclude genetic cause. All basic investigations were carried out including $\mathrm{CBC}$, stool $\mathrm{C} / \mathrm{E}, \mathrm{RBS}$, S. Ca., S. Electrolytes, RFT, CXR, X-ray wrist for bone age and $A B G$ 's. After that patients having endocrinal issues were excluded (via thyroid profile and insulin stress test) and antitissue transglutaminase $\lg A \& \lg G$ \& total serum $\lg A$ were carried out.

Then patients having TTG titer $>10$ times of the normal, were considered positive for celiac disease and biopsy not carried out. ${ }^{12-14}$ However, patients having equivocal results and having increased titer. But less than 10 times of the normal were advised to have intestinal biopsy for confirmation of celiac disease.

\section{RESULTS}

Out of 300 patients, 174 were females $\& 126$ were males. (Table 1) and their age group frequency is shown in Table 2.

Table 1: Gender frequency and distribution

\begin{tabular}{|c|c|c|c|c|}
\hline Group & Males & $\%$ & Females & $\%$ \\
\hline Without celiac & 84 & $46.6 \%$ & 96 & $53.33 \%$ \\
\hline With celiac & 42 & $35 \%$ & 78 & $65 \%$ \\
\hline Total & 126 & $42 \%$ & 174 & $58 \%$ \\
\hline
\end{tabular}

Table 2: Age and frequency distribution

\begin{tabular}{|c|c|c|c|}
\hline Group & Age Group & Frequency & $\%$ \\
\hline \multirow{3}{*}{ Without celiac } & 2-6 year & 45 & $25 \%$ \\
\cline { 2 - 4 } & $7-11$ year & 114 & $63.33 \%$ \\
\cline { 2 - 4 } & $12-15$ year & 21 & $11.66 \%$ \\
\hline \multirow{3}{*}{ With celiac } & $2-6$ year & 39 & $32.5 \%$ \\
\cline { 2 - 4 } & $7-11$ year & 63 & $52.2 \%$ \\
\cline { 2 - 4 } & $12-15$ year & 18 & $15 \%$ \\
\hline
\end{tabular}

120 patients (40\%) were diagnosed as celiac disease and Out of 120 patients of celiac disease 78 were females and only 21 were male.
88 patients were having TTG titer $>10 \%$ of the normal value so they were excluded from biopsy. 29 patients were having increased titer but less than 10 times of the normal value and 7 patients were found to have equivocal results. Those 29 patients were found positive for celiac disease at biopsy finding. Out of 7 patients $(2.3 \%)$ having equivocal results 3 patients $(1 \%)$ were found positive for celiac disease and 4 patients $(1.3 \%)$ were found negative.

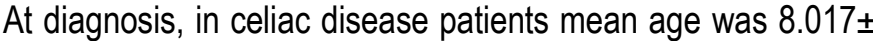
2.535. Mean weight was $19.037 \pm 5.419 \mathrm{~kg}$. Mean height was $113.013 \pm 15.127 \mathrm{~cm}$. it was found that 117 patients $(97.5 \%)$ with celiac disease were at 2 SD and only 3 Patients $(2.5 \%)$ were at 3SD with celiac disease. (Table 3) No patient was found $\lg$ A deficient. All the biochemical tests were found unremarkable in both celiac and non-celiac group.

Table 3: Mean Age, weight \& height in study group

\begin{tabular}{|c|c|c|c|c|c|}
\hline \multirow{2}{*}{ Group } & \multirow{2}{*}{ Age } & \multirow{2}{*}{ Weight } & Height & \multicolumn{2}{|c|}{ SD } \\
\cline { 5 - 7 } & & & >2SD & >3SD \\
\hline Without & $8.368 \pm$ & $20.483 \pm$ & $116.518 \pm$ & 171 & 9 \\
celiac & 2.387 & 5.803 & 12.634 & 171 & \\
\hline $\begin{array}{c}\text { With } \\
\text { celiac }\end{array}$ & $\begin{array}{c}8.017 \pm \\
2.535\end{array}$ & $\begin{array}{c}19.037 \pm \\
5.419\end{array}$ & $\begin{array}{c}113.013 \pm \\
15.127\end{array}$ & 117 & 3 \\
\hline Total & $\begin{array}{c}8.25 \pm \\
2.432\end{array}$ & $\begin{array}{c}19.89 \pm \\
5.243\end{array}$ & $\begin{array}{c}114.02 \pm \\
17.505\end{array}$ & 288 & 12 \\
\hline
\end{tabular}

\section{DISCUSSION}

This study demonstrated prevalence of celiac disease in significant number of patients $(n=120)$ that is $40 \%$ among children $(n=300)$ with short stature, who do not have obvious underlying cause for their short stature. The prevalence of celiac disease in children with idiopathic short stature that has been studied up-till now in different regions of the world has ranged from 0.05 to $59.1 \%$ depending on geographical diversity. ${ }^{13}$ The prevalence of celiac disease in general population is 1:300 to 1:100. ${ }^{1}$ So we see that our study group patients showed a high prevalence. This might be due to the fact that there had been increasing pattern of atypical celiac disease in recent years and we detect only a small number of patients due to little awareness in public and low socioeconomic status is also a big hindrance as screening tests are expensive. Increase sampling will definitely lead to better recognition of the disease.

In our study male to female ratio was 1:1.8. Most of the studies conducted in Pakistan up-till now for prevalence of celiac disease showed a clear female predominance. ${ }^{16}$ Environmental factors might play role in this because sex hormones are not likely to be the explanation.

Mean age of diagnosis was $8.368 \pm 2.387$ years, that was quite earlier in comparison with other studies conducted in Iran in which it was 16 years. ${ }^{10}$ Patients with classical symptoms of celiac disease are diagnosed earlier. However, recognition of celiac disease with atypical presentation is really a challenge for pediatricians. Although increasing awareness about the disease has solved much of the problem so we can say that we are able to recognize monosymptomatic celiac disease (short stature) by keeping our threshold low for diagnosing it. 
Most of the patients diagnosed with CD were at 2SD (97.5\%) and only $2.5 \%$ patients were at $3 \mathrm{SD}$. It may be due to the reason that patients at 3SD may have other symptomatology and clinical signs.

All biochemical tests were found normal in our patients. This is in accordance with other studies also. ${ }^{13,16}$ The exact mechanism of short stature as a monosymptomatic presentation in children with celiac disease is not clearly understood but it might be multifactorial. 4,17

The final adult height can be improved if the patients are diagnosed and managed earlier. However, patients remain slightly shorter as compared to the general population despite adopting gluten free diet.

\section{CONCLUSION}

We conclude that prevalence of celiac disease is high in patients with Idiopathic short stature and it is important to investigate all children with ISS for celiac disease by measuring TTG antibodies. Patients effected by celiac disease did not differ from those without celiac disease. So, patients with short structure should be evaluated for celiac disease even in the absence of clinical symptoms.

\section{LIMITATIONS OF STUDY}

There are some limitations of our study too. Although the sensitivity and specificity of serological tests are high ${ }^{12,13}$ but definitive diagnosis of celiac disease is based on intestinal biopsy and we could not plan biopsy for all the patients because of our limited resources and relied on the high level of antitissue transglutaminases.

\section{SUGGESTIONS / RECOMMENDATIONS}

We suggest a further collaborative study involving the other health institutes of Faisalabad to know the actual burden of the disease in our region.

\section{CONFLICT OF INTEREST / DISCLOSURE}

There is no conflict of interest involved.

\section{ACKNOWLEDGEMENT}

The authors acknowledge the efforts of all colleagues and junior doctors for collection of data, lab technicians and radiologists of Children Hospital Faisalabad for providing a technical support.

\section{REFERENCES}

1. Troncone R, Shamir R. Celiac Disease (Gluten Sensitive Enteropathy). Nelson of Ped. 2019:364(2);7908-24.

2. Asghar A, Zafar MH, Munir S. Frequency of celiac disease in patients presenting with nutritional anemia. APMC 2018;12(2):151-3.

3. Taheri M, Sabzali S, Hakim A, Sajadi N, Hakimzade M, Ziaeikajbaf T, Cheraghian B. The prevalence of celiac disease in children with unexplained failure to thrive in southwest of Iran. Int J Pediatr. 2017;5(4):4663-9.

4. Pinto-Sánchez MI, Bercik P, Verdu EF, Bai JC. Extraintestinal manifestations of celiac disease. Dig Dis. 2015;33(2):147-54.

5. Meazza C, Pagani S, Laarej K, Cantoni F, Civallero P, Boncimino A, Bozzola M. Short stature in children with celiac disease Pediatr Endocrinol Rev. 2009;6(4):457-63.

6. Rubio-Tapia. A, Hill ID, Kelly CP, Caldawood AH, Murray JA. Amercian College of gastroenterology (ACG) clinical guidelines: diagnosis and management of celiac disease. Am $J$ Gastroenterol. 2013;108(5):656-76.

7. Nasir MA, Assiri AMA. Celiac disease in children with short stature; A hospital-based study. J Taibah Uni Med. Sci. 2013;8(2):93-6.

8. Singh P, Sharma PK, Agnihotri A, Jyotsna VP, Das P, Gupta SD, Das $P$ etal. Celiac disease in patients with short stature: A tertiary care centre experience. Natl Med J India. 2015;28(4):176-80.

9. Reilly NR, Green PHR. Epidemiology and clinical presentations of celiac disease. Semin Immunopathol. 2012;34(4):473-8.

10. Hashemi J, Hajiani E, Shahbazin HBB, M. Rahin, G. Navab: Prevalence of celiac disease in Iranian children with idiopathic short stature. World J Gastroenterol. 2008;14(48):7376-80.

11. Popp A, Kivela L, Fuchs V, Kurppa K. Diagnosing Celiac Disease: Towards Wide-Scale Screening and Serology-Based Criteria? Gastroenterol Res Pract. 2019; 2019: 2916024.

12. Ehsani - Ardakani MJ, Rostami Nejad M, Villanacci V, Volta U, Manenti S, Caio G. et al. Gastrointestinal and non-GI, presentation in patients with celiac disease. Arch Iran Med. 2013;16(2):78-82.

13. Singh $P$, Kurray L, Agnihotri A, Das $P$, Verma AR, Sreenvias $V$, Data Gupta S, Makharia GK. Titres of antitissue transglutaminase antibody correlate well with severity of villous abnormalities in celiac disease. J Clin gastroenterol. 2015;49(3):212-7.

14. Lebwohl B, Green PHR. Antitissue transglutaminase Ig A for celiac disease testing. JAMA. 2016;315(1):81-2.

15. Aldaghi MA, Dehghani SM, Haghighat $M$. evaluation of the correlation between TTG titer and duodenal biopsy finding in children with suspected celiac disease. Iran $\mathrm{J}$ Pediatr. 2016;26(1):e3615.

16. Javaed A, Shah W, Ghauri SK. Gender Prevalence in Celiac Disease. Adv. Basic Med Sci. 2017;1(2):48-50.

17. Leffler DA, Green PHR, Fasano A. Extraintestinal manifestations of celiac disease. Nat Rev Gastroenterol Hepatol. 2015;12(4):561-71. 


\section{AUTHORSHIP AND CONTRIBUTION DECLARATION}

\begin{tabular}{lc|c} 
AUTHORS & Contribution to The Paper & Signatures \\
\hline $\begin{array}{l}\text { Dr. Jaweria Masood } \\
\text { Senior Registrar Pediatric Medicine } \\
\text { Children Hospital, Faisalabad Pakistan }\end{array}$ & Script Writing \\
\hline $\begin{array}{l}\text { Dr. Hooria Rehman } \\
\text { Fellow Gastroenterology \& Hematology } \\
\text { Children Hospital \& ICH, Lahore Pakistan }\end{array}$ & Data Collection \\
\hline $\begin{array}{l}\text { Dr. Zahid Mahmood Anjum } \\
\text { Assistant Professor Pediatrics } \\
\text { Children Hospital, Faisalabad Pakistan }\end{array}$ & Reference Writing \\
\hline $\begin{array}{l}\text { Dr. Iram Iqbal } \\
\text { Senior Registrar Pediatrics Medicine } \\
\text { Children Hospital, Faisalabad Pakistan }\end{array}$ & Data Collection \\
\hline $\begin{array}{l}\text { Dr. Sadia Zafar } \\
\text { Assistant Professor Pediatrics } \\
\text { Allied Hospital, Faisalabad Pakistan }\end{array}$ & Data Collection \\
\hline $\begin{array}{l}\text { Prof. Dr. Hina Ayesha } \\
\text { Professor of Pediatric Medicine } \\
\text { Allied Hospital, Faisalabad Pakistan }\end{array}$ & Proof Reading
\end{tabular}

